\title{
Refined Spruce Resin to Treat Chronic Wounds: Rebirth of an Old Folkloristic Therapy
}

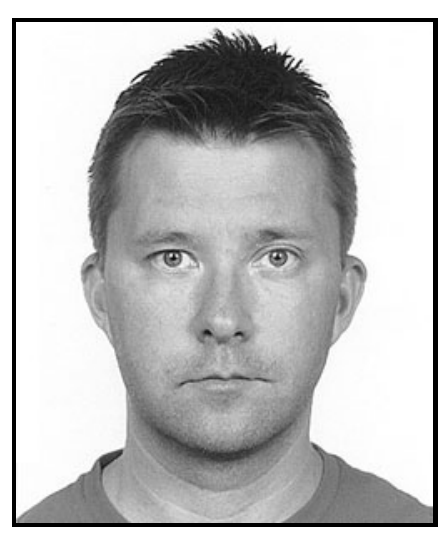

Janne J. Jokinen, MD, PhD

Submitted for publication August 6, 2013 Accepted in revised form November 6, 2013.

${ }^{*}$ Correspondence: Heart and Lung Center Helsinki University Hospital, P.0. Box 340, Fl00029 Helsinki, Finland (e-mail: janne.jokinen@ helsinki.fi).

\author{
Janne J. Jokinen ${ }^{1, *}$ and Arno Sipponen ${ }^{2}$ \\ ${ }^{1}$ Heart and Lung Center, Helsinki University Hospital, Helsinki, Finland. \\ ${ }^{2}$ Department of Orthopedics and Traumatology, Päijät-Häme Central Hospital, Lahti, Finland.
}

Significance: The treatment of chronic wounds results in an enormous drain on healthcare resources in terms of workload, costs, frustration, and impaired quality of life, and it presents a clinical challenge for physicians worldwide. Effective local treatment of a chronic wound has an important role, particularly in patients who are-because of their poor general condition, diminished life expectancy, or unacceptable operative risk-outside of surgical treatment. Recent Advances: Since 2002, our multidisciplinary research group has investigated the properties of Norway spruce (Picea abies) resin in wound healing and its therapeutic applications in wound care. Resin is a complex mixture of resin acids (e.g., abietic, neoabietic, dehydroabietic, pimaric, isopimaric, levopimaric, sandrakopimaric, and palustric acids) and lignans (e.g., pino-, larici-, matairesinol, and p-hydroxycinnamic acid) having substantial antimicrobial, wound-healing, and skin regeneration enhancing properties.

Critical Issues: The cornerstone in successful wound care is an efficient causal treatment of the underlying co-morbidities, for example, diabetes, malnutrition, vascular- or certain systemic diseases. However, definitive diagnosis and specific therapy of a chronic wound is often difficult, because the etiology is practically always multi-factorial, and in the chronic phase, confounding factors such as infections invariably impede wound healing.

Future Directions: To study the exact molecular mechanism of actions by which resin promotes cellular regeneration and epithelialization during the wound-healing process. To investigate potential antimicrobial properties of resin against the most ominous multidrug-resistant beta-lactamase (including carbapenemases and metallo- $\beta$-lactamases) producing bacteria, and to individualize those pharmacologically active compounds which are responsible for the antimicrobial activity of resin.

\section{SCOPE AND SIGNIFICANCE}

Although AT LEAST 170 topical wound care products are available, ${ }^{1,2}$ well-designed randomized and controlled clinical trials regarding wound care products are rare, and the number of case-control or observational studies is limited..$^{3-5}$ It is estimated that the care of chronic wounds in the United States costs 6-15 billion U.S. dollars annually. ${ }^{6}$ The annual wound care costs in Denmark, a country with similar demo- graphics to that of Finland, are estimated to be around 100 million euros. ${ }^{7}$ From the perspective of patients, community, and health-care resources, a new, safe, clinically- and cost-effective method for the treatment of chronic wounds would be undoubtedly welcome.

\section{TRANSLATIONAL RELEVANCE}

Our multidisciplinary research group in Finland has investigated 
the properties of Norway spruce (Picea abies) resin in the treatment of acute- and chronic-, either infected or noninfected, wounds for more than 10 years now. ${ }^{2,8-17}$ As a result of this comprehensive translational research program, we have succeeded in showing through basic, clinical, and applied research that resin treatment in wound care is feasible and clinically effective. As far as we know, our research work regarding the medical use of spruce resin and its clinical applications in modern medicine are pioneering and globally unique.

\section{CLINICAL RELEVANCE}

A $10 \%$ salve prepared from pure resin of Norway spruce is strongly antimicrobial against a wide range of bacteria and fungi. ${ }^{10-17}$ Resin is a strong inhibitor of interleukin 1-beta, matrix metalloproteinase-3, and tumor necrosis factor alpha in the inflammation process, and the anti-inflammatory potential of components of resin is even superior to that of $0.5 \mu \mathrm{M}$ dexamethasone (MD Biosciences, Inc., Glasgow, UK). Resin salve is a promising treatment option in infected or noninfected, acute or chronic, surgical or nonsurgical wounds and pressure ulcers. It has been shown in a clinically relevant, prospective, and randomized setting that resin salve promotes the healing of severe pressure ulcers more effectively than standard treatment with hydrofiber dressings. ${ }^{10}$

\section{BACKGROUND}

The oldest accounts of the therapeutic effects of coniferous resin stem from ancient Egypt, where salve prepared from resin was used to treat burns. ${ }^{18,19}$ In the Nordic countries, especially in Finnish Lapland, ointment prepared from the Norway spruce (P. abies; Fig. 1) resin has been used for centuries to treat acutely and chronically infected wounds, sores, pressure ulcers, punctured abscesses, suppurating burns, onychomycosis, and paronychia. ${ }^{20}$ Although treatment with resin is an old folkloristic therapy and empirical experience over time has shown the effectiveness of resin treatment, only at the beginning of the twenty-first st century have researchers conducted systematic studies of its effectiveness and mechanisms of action.

\section{EXPERIMENTAL METHODS}

\section{Determination of antimicrobial effect and mechanisms of action of resin}

Agar diffusion tests. Agar diffusion tests were applied to test the antimicrobial effects of resin against various strains of bacteria and fungi. In

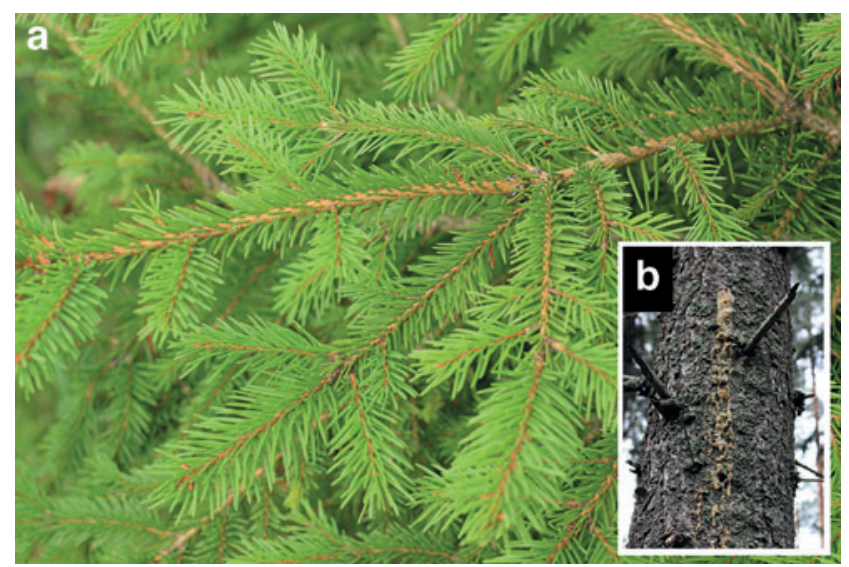

Figure 1. Norway spruce [Picea abies; (a)] and secreted resin from the trunk of the tree (b). To see this illustration in color, the reader is referred to the web version of this article at www.liebertpub.com/wound

terms of bacteria, Muller-Hinton (Scharlau Chemie S.A., Barcelona, Spain) medium was chosen as the agar and used according to the guidelines of the Clinical and Laboratory Standards Institute (CLSI). ${ }^{21}$ Using Mueller-Hinton agar plates, wells with a diameter of $8 \mathrm{~mm}$ were punched into the agar medium and filled with the resin salve. The plates were incubated at $35^{\circ} \mathrm{C}$ in ambient air for $18 \mathrm{~h}$ before measuring zones of inhibition. Wells filled with sterile saline without resin salve were used as controls.

Agar dilution tests. The minimal inhibitory concentration (MIC) plates were prepared with a slight modification of a method used in essential oil research. ${ }^{22}$ Tween 80 (Fluka AG., Buchs, Switzerland) was added to Mueller-Hinton (Scharlau Chemie S.A., Barcelona, Spain) media to give a concentration of $1 \%(\mathrm{w} / \mathrm{v})$ with the addition of $1 \%$ $(\mathrm{w} / \mathrm{v})$. Pulverized spruce resin was added to $500 \mathrm{~mL}$ aliquots of liquid agar to give final concentrations of $1 \%, 0.8 \%, 0.6 \%, 0.4 \%$, and $0.2 \%(\mathrm{w} / \mathrm{v})$ in the media. The bacteria used in the MIC experiments were grown overnight at $35^{\circ} \mathrm{C}$ on Mueller-Hinton agar. Bacterial biomass was suspended in $0.9 \%$ sodium chloride solution and adjusted to match the 0.5 McFarland turbidity standards. Three 1-mL aliquots of the bacterial suspensions were delivered onto the surface of three parallel Mueller-Hinton/ resin plates using a calibrated loop. Bacterial growth was inspected after $16-20 \mathrm{~h}$. Plates that did not show any bacterial growth at $1 \%(\mathrm{w} / \mathrm{v})$ spruce resin concentration after $16-20 \mathrm{~h}$ were incubated for 5 days.

Liquid media experiments. Liquid media experiments were performed to assess the antimicrobial 
threshold concentration of resin on selected bacteria. The growth medium used in liquid media experiments was nutrient-rich fastidious anaerobe broth (FAB; Lab M Ltd., Bury, United Kingdom). The experiments with the FAB medium were performed in two ways. First, the tested bacteria were inoculated into $1 \mathrm{~mL}$ FAB medium with or without a drop $(0.05 \mathrm{~mL})$ of resin salve. In the FAB tubes, colonization of the bacteria was examined by turbidity of the growth medium and recorded as absent, mild, moderate, or heavy (Fig. 2). Second, FAB media with or without pretreatment with resin salve were prepared. For preparing the resinpretreated FAB medium, a layer of resin salve was spread on the bottom of a Petri dish, after which $12 \mathrm{~mL}$ of FAB solution was layered onto this resin bed. The plate was covered by Parafilm and incubated at room temperature from $15 \mathrm{~min}$ to $72 \mathrm{~h}$ alternately. After incubation, the FAB medium was removed from the plate with a Pasteur pipette. The FAB media with or without pretreatment with resin were used in incubation experiments with various bacteria. After pretreatment with resin, the FAB medium was clear and did not differ macroscopically from the FAB medium that was not pretreated with resin. However, the $\mathrm{pH}$ of the medium was slightly lower after pretreatment (6.5 vs. 7.6). The inoculum of bacteria to be tested was prepared by making a saline suspension of isolated colonies that were selected from an 18 to $24 \mathrm{~h}$ blood agar plate. The suspension was adjusted to match the $0.5 \mathrm{McF}$ arland turbidity standards and serially diluted (10-fold) from $10^{-1}$ to $10^{-6}$. An inoculum of $100 \mu \mathrm{L}$ of undiluted suspension and appropriate dilutions were added to each tube with $900 \mu \mathrm{L}$ of medium. Control cultures were inoculated in tubes without resin or without pretreatment of the test medium with resin. The tubes were incubated at $35^{\circ} \mathrm{C} \pm 2{ }^{\circ} \mathrm{C}$ for $18 \mathrm{~h}$ for the first inspection and further for approximately $72 \mathrm{~h}$.

European Pharmacopoeia challenge test. The antimicrobial properties of resin and MIC levels for specific bacterial and fungal strains were further elucidated and confirmed with the European Pharmacopoeia (EP) challenge test. ${ }^{23,24}$ The EP test consists of a specific set of common microorganisms against which the antimicrobial action of the challenge medium (preservation of the microorganisms in the challenge medium) is tested. The microbes will remain viable and re-cultivable from the challenge medium if the medium does not exert any microbistatic or microbicidal influences. Resin media for the EP challenge test were prepared by mixing the purified resin, as described earlier, with a biologically inert salve so that the resin content in the final medium was $0.5 \%, 2 \%$, or $10 \%$. The salve medium without resin was used as a control.

The density of the inoculation was in the range of $10^{4}-10^{6}$ colony-forming units $(\mathrm{cfu}) / \mathrm{mL}$, or $\mathrm{cfu} / \mathrm{g}$ according to the EP. The re-growth of bacteria from the challenge medium was assayed at 1 or $48 \mathrm{~h}$, or 7 , 14 , and 28 days. To focus on early inhibition rate, modified time intervals were used at 1 or $24 \mathrm{~h}$, or 4 , 7 , and 14 days. Samples taken at different time intervals were cultured in specific microbiological media, and a reduction in the number of microbial cfu in test samples as a function of time was used to measure the antimicrobial influence. The reduction of bacteria by at least $10^{2} \mathrm{cfu}$ within $48 \mathrm{~h}$ and at least $10^{3}$ within 7 days was considered as indicating significant antibacterial activity of the medium.

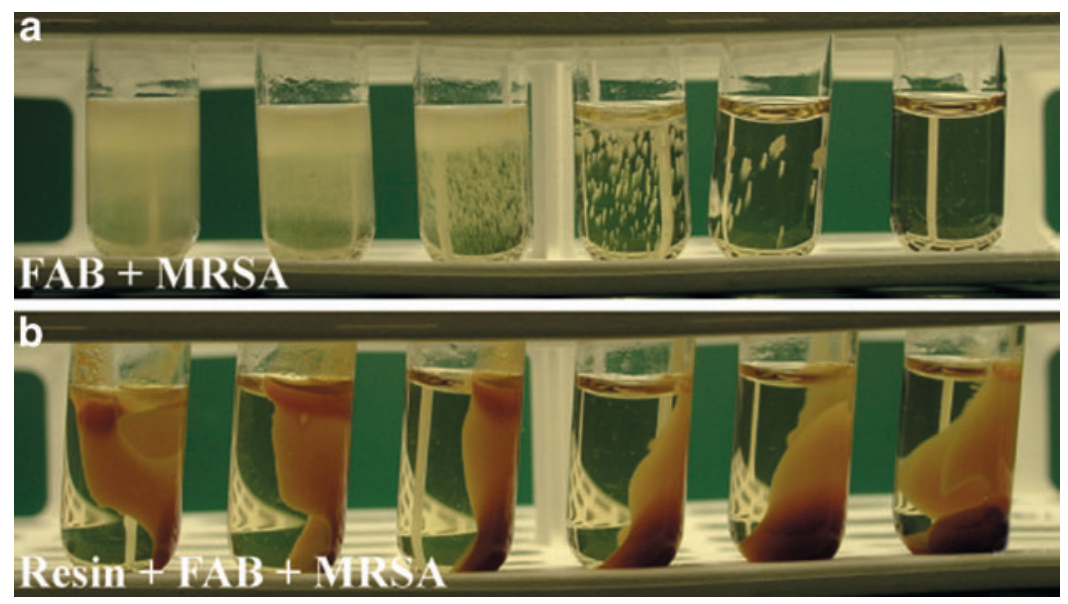

Figure 2. Methicillin-resistant Staphylococcus aureus (MRSA) culture in fastidious anaerobe broth (FAB) medium with decreasing MRSA concentrations from left to right (a). Inhibition of growth of MRSA in FAB medium pretreated with resin (resin-FAB + MRSA), that is, before inoculation of MRSA; the FAB medium was absorbed for $1 \mathrm{~h}$ with resin (b). To see this illustration in color, the reader is referred to the web version of this article at www.liebertpub.com/wound 
Each tested microbe was added as $1 \mathrm{~mL}$ aliquots $\left(5 \times 10^{5} \mathrm{cfu} / \mathrm{mL}\right.$ [bacteria] and $5 \times 10^{4} \mathrm{cfu} / \mathrm{mL}$ [fungi]) into $10 \mathrm{~g}$ of the resin-salve challenge medium. The medium was incubated at room temperature, and samples were taken at the previously stated time points after the inoculation for the re-cultivation of the microorganisms in the culture medium. All inoculated microorganisms were re-cultivable at $1 \mathrm{~h}$ after inoculation from resin-salve media to the same extent as from the control challenge medium (salve medium without resin). This level of re-growth was considered strong $\left(>10^{3} \mathrm{cfu} / \mathrm{mL}\right.$ ) and was used as a reference in calculations regarding bacteriostatic and fungistatic impact. The reduction of the re-growth from the reference $\left(>10^{3} \mathrm{cfu} / \mathrm{mL}\right)$ to strong $\left(10^{2} \mathrm{cfu} /\right.$ $\mathrm{mL}$ ) and mild (1-10 cfu/mL) or absent (no re-growth) was considered as indicating a significant bacteriostatic or fungistatic effect, corresponding to the growth reduction of bacteria by $10^{3} \mathrm{cfu} / \mathrm{mL}$ or of fungi by $10^{2} \mathrm{cfu} / \mathrm{mL}$ or more.

Electron microscopy. Transmission electron microscopy (TEM) and scanning electron microscopy (SEM) studies were performed in both bacterial and fungal cells to reveal morphological changes at the cellular level after exposure of the cells to resin. ${ }^{25}$ In bacteria-related electron microscopy experiments, Staphylococcus aureus was incubated for $24 \mathrm{~h}$ at $37^{\circ} \mathrm{C}$ in Tryptone Soy media (Merck GmbH, Darmstadt, Germany). In the exposure studies, cultures of $S$. aureus strain $1 \times 10^{6} / \mathrm{mL}$ stock cultures were transferred onto solid, purified resin that was 1-2 mm thick, $10 \%$ (w/w) resin salve, or a salve base in Petri dishes, which were incubated for $18 \mathrm{~h}$ at $37^{\circ} \mathrm{C}$, after which the electron microscopy specimens were prepared. The samples for TEM were removed from cultures and prefixed in phosphate-buffered $(\mathrm{pH} \mathrm{7.2)} 2.5 \%$ glutaraldehyde with tannic acid for $2 \mathrm{~h}$ at room temperature. All samples were postfixed with $1 \%$ phosphate-buffered osmium tetroxide, dehydrated, and embedded in Epon. After polymerization of the Epon, thin sections were prepared with an ultramicrotome, and the sections were collected on grids and poststained with uranyl acetate and lead citrate. The TEM micrographs were taken with a JEM-1200EX device (Jeol Ltd., Tokyo, Japan) at $60 \mathrm{kV}$. For the SEM, the bacteria were fixed, dehydrated, and dried from hexamethyldisilazane. The SEM micrographs were taken with a JSM$6335 \mathrm{~F}$ field emission SEM (Jeol Ltd.) at $15 \mathrm{kV}$.

Electrophysiology. The effect of resin and abietic acid on the membrane potential of $S$. aureus cells was measured by flow cytometry (LSR II; BD
Biosciences Ltd., Franklin Lakes, NJ) and the BacLight Bacterial Membrane Potential Kit (Molecular Probes ${ }^{\circledR}$ B34950, Carlsbad, CA). In exposure experiments, resin or abietic acid (Karl Roth $\mathrm{GmbH}$, Karlsruhe, Germany) was transferred to glass beakers with a bottom diameter of $5.7 \mathrm{~cm}$ and kept overnight in $80^{\circ} \mathrm{C}$. The thickness of the layers of cooled, solidified resin and abietic acid at the bottoms of the beakers was $1 \mathrm{~cm}$. Diluted $S$. aureus suspension $(4 \mathrm{~mL})$ was poured onto resin, abietic acid, and empty beakers in duplicate. The beakers were covered with Parafilm and incubated for $90 \mathrm{~min}$ on a horizontal shaker $(100 \mathrm{rpm} / 90 \mathrm{~min})$ at room temperature. After incubation, $1 \mathrm{~mL}$ of bacterial suspension from each beaker was pipetted into three plastic cuvettes. ${ }^{16}$ The cuvettes were incubated for $30 \mathrm{~min}$ at room temperature before flow cytometry. For flow cytometry, an excitation wavelength of $488 \mathrm{~nm}$ was used, and the fluorescence was measured at $615 \mathrm{~nm}$ (red) and $518 \mathrm{~nm}$ (green). The mean fluorescence intensity (MFI) ratiometric parameter $\left(\mathrm{MFI}_{\text {red }}: \mathrm{MFI}_{\text {green }}\right)$ describes the strength of the membrane potential. When the
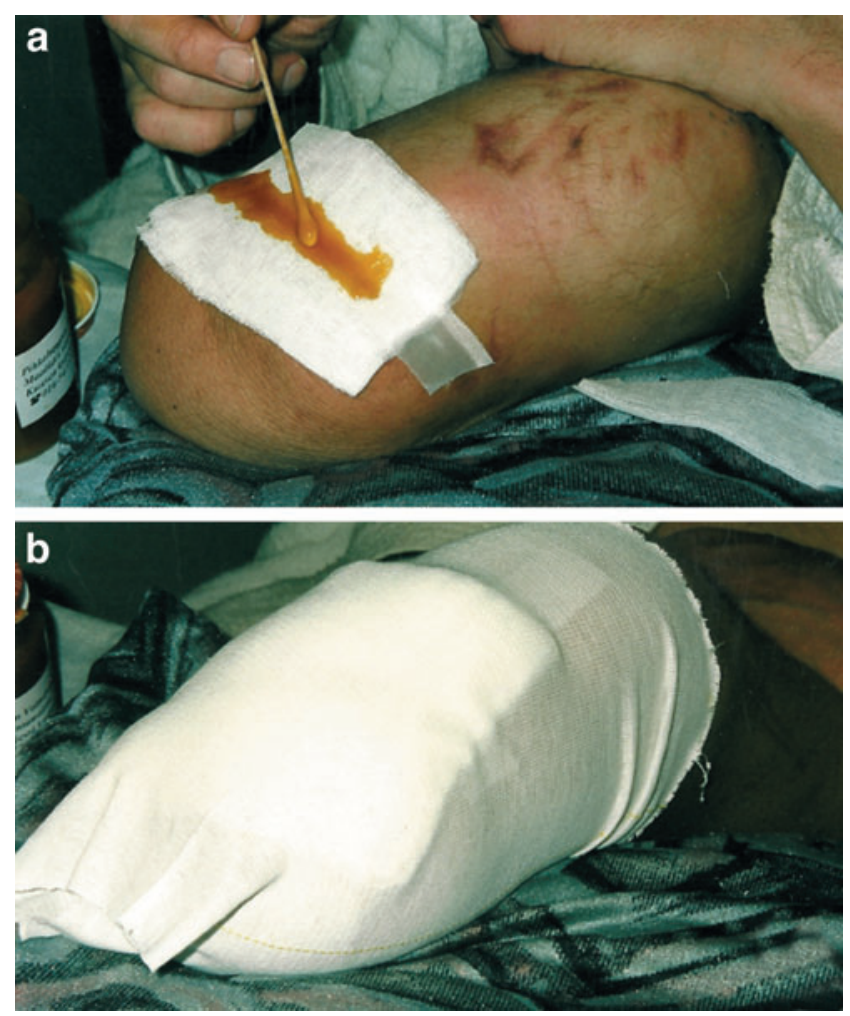

Figure 3. Resin salve is spread either directly onto the wound or onto the first wound cover of a bandage (a), after which the wound area is covered with gauze (b). The resin-gauze dressing is changed daily if the wound is infected or produces a discharge. If this is not the case, the dressing is changed every third day. To see this illustration in color, the reader is referred to the web version of this article at www.liebertpub.com/wound 
potential is reduced, the ratiometric parameter decreases as the intensity of the green fluorescence increases.

Clinical use of resin. The salve prepared from resin may be spread directly onto the wound, after which the area is covered with a bandage that is suitable for local wound care. The bandage prohibits salve from moving away from the wound area. If the skin condition is more widespread or contains cavities or fistulae, the salve may be spread as a film with a thickness of at least $1 \mathrm{~mm}$ onto a gauze or gauze ribbon that is then used to fill the cavity or fistulae channel. Dressings are changed every 1-3 days, depending on the amount of wound secretion. It is important to prevent salve-prepared bandages from drying and becoming affixed to the wound (Fig. 3). Surgical debridement at bedside on local anesthesia is recommendable if the wound comprises profusely debris or necrotic tissue.

Contraindications. Sensitivity to natural resins manifests clinically as local allergic contact dermatitis. ${ }^{26}$ In Finland, from 1990 to 1996, 0.9\% of allergic reactions (24/2646 of patients) reported to the Finnish National Register of Occupational

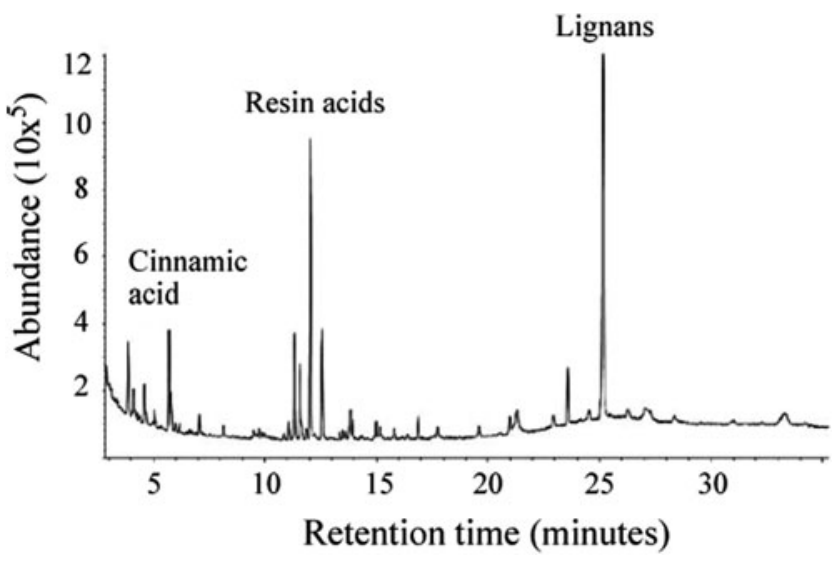

Figure 4. Profile of extracts of spruce resin detected by gas-liquid chromatography and identified with mass spectra. Resin acids and lignans are the major compounds that are detected in water extract of the resin.

Diseases were caused by conifers or teak. ${ }^{27} \mathrm{Al}-$ though hypersensitivity caused by conifers is infrequent, the risk of resin sensitivity should be taken into consideration in clinical practice. Resin treatment is not suitable for patients who are allergic to resin. Resin allergy may be studied by epicutaneous testing with a test substance containing $20 \%$ resin. The sensitivity of this test is
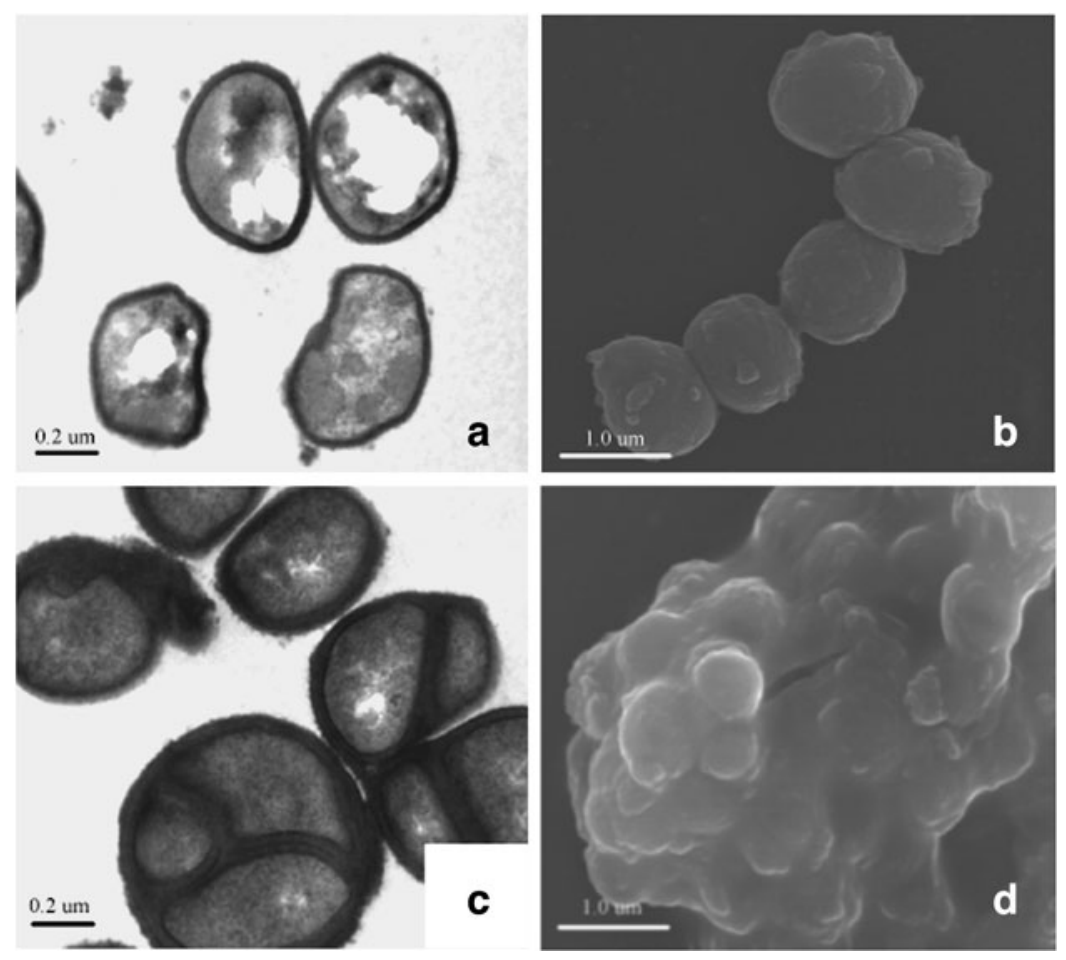

Figure 5. Effect of resin on the cell wall and cell division of $S$. aureus. Panels are transmission (a) and scanning (b) electron micrographs of the normal $S$. aureus bacterium. (c, d) Exposure of $S$. aureus to resin for $18 \mathrm{~h}$ caused the cell wall to thicken significantly and the bacteria and mitosis to cease. 
$\sim 50 \%$. Approximately 5-30\% of all people with allergy to deodorants react to natural resins in epicutaneous testing.

\section{DISCUSSION OF FINDINGS AND RELEVANT LITERATURE}

\section{Mechanisms of action of resin in therapeutic applications}

Resin protects plants against a wide range of plant pathogens, including bacteria, fungi, protozoans, archaea, and parasites. Resin is a hydrocarbon secretion of coniferous trees such as Norway spruce (P. abies) and Scots pine (Pinus sylvestris), and a complex mixture of resin acids, lignans, and cinnamic acid. Resin acids belong to a group of chemical compounds called diterpenes, and they form the major part of all resin components. Resin acids have a hydrophobic $\left(\mathrm{CH}_{3}\right)$ and a hydrophilic (-COOH) portion, which makes them partly water soluble, although the resin, as such, does not dissolve in water. The most common resin acids found in spruce resin are abietic, neoabietic, dehydroabietic, pimaric, isopimaric, levopimaric, sandracopimaric, and palustric acids. The resin excreted by the coniferous trees is mixed with lignans as pinoresinol, lariciresinol, and matairesinol (Fig. 4). ${ }^{17}$

In culture experiments and electron microscopic studies, coniferous resin seems to destroy the bacterial cell wall and cell membrane. Bacterial cell walls are thickened, and the cells are aggregated and finally degraded when bacteria are exposed to resin (Fig. 5). Studies with bacteria suggest that this action causes nonspecific damage and is mediated by terpenic resin acids. ${ }^{13-16}$

In electrophysiological experiments, exposure of $S$. aureus to resin decreases the cell membrane proton gradient in bacterial cells. This phenomenon is considered to be associated with a disruption in proton transport in the membrane-bound adenosine triphosphatase, resulting in the uncoupling of oxidative phosphorylation. Subsequently, the cell metabolism ceases and the energy supply is lost. This mechanism would also explain the bacteriostatic and fungistatic effect of resin. A bacterial or fungal cell that cannot produce adenosine triphosphate does not necessarily die, but it cannot undergo mitosis. ${ }^{16}$

The lignans that dissolve from the resin into water probably contribute significantly to wound healing and represent a biologically active component of resin. Lignans have anti-oxidative properties against deleterious effects of free radicals, and they may change through microbial metabolism and possibly other mechanisms into components that, in their biological environment and through the impact of bacterial effects, become hormone like. ${ }^{17}$ We speculate that lignan-originated phytoestrogens may contribute to cellular regeneration and accelerate wound healing.

\section{Current clinical evidence for resin as therapy in modern medicine}

The first modern medical report on resin's beneficial effects for pressure ulcers was published as a case study in the Finnish Medical Journal in 2003. ${ }^{8}$ We described two patients, aged 61 and 100 years, respectively, who had been permanently treated in the long-term ward for their poor overall condition, and whose severe pressure ulcers in the heel and sacrum were successfully cured with resin (Fig. 6). The first international case report in English was published in $2007 . .^{9}$ In that report, we described a man, aged 51 years, who had been in a motorbike accident and whose severely infected amputation stump of the lower leg was, against all expectations of the orthopedic surgeon, plastic surgeon, and in-
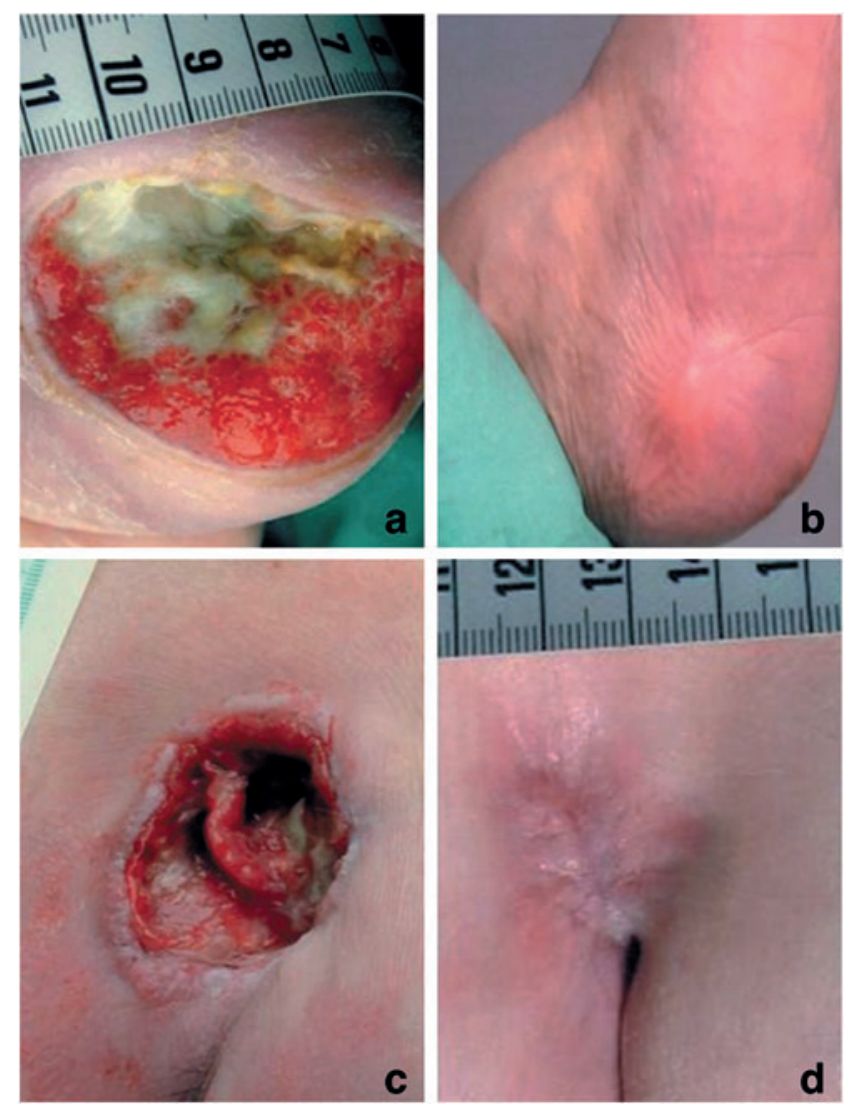

Figure 6. Pressure ulcer on the heel of a 100 -year-old female patient before (a) and 6 months after (b) treatment with resin salve. Pressure ulcer on the sacrum of a 61-year-old male patient before (c) and 7 months after (d) treatment with resin salve. To see this illustration in color, the reader is referred to the web version of this article at www.liebertpub.com/wound 
fection control specialist, successfully cured with topical resin treatment (Fig. 3).

Given these hints at therapeutic efficacy, we initiated in 2005 a prospective, randomized, controlled multicentre trial to study the clinical effectiveness of resin in the treatment of severe pressure ulcers. The study involved 37 patients with grade II-IV pressure ulcers in 11 primary care hospitals in Finland. All ulcers were graded according to the European Pressure Ulcer Advisory
Panel (EPUAP) recommendations ${ }^{28}$ and allocated randomly to receive either topical $10 \%(\mathrm{w} / \mathrm{w})$ resin salve or sodium carboxymethylcellulose hydrocolloid polymer treatment (Aquacel ${ }^{\circledR}$ or Aquacel $\mathrm{Ag}^{{ }^{\circledR}}$; ConvaTec Ltd., London, United Kingdom).

The primary outcome measures were the proportion of completely healed ulcers within 6 months and the healing of the ulcers over time. The secondary outcome measures were partial healing of ulcers, that is, improvement of ulcer grade during

Table 1. Antimicrobial effect of resin in microbial cultures and in the European Pharmacopoeia challenge test

\begin{tabular}{|c|c|c|c|}
\hline Parameter & Culture & EP-Challenge Test & Microbial Strain \\
\hline \multicolumn{4}{|l|}{ Gram-positive cocci } \\
\hline Staphylococcus aureus ${ }^{\mathrm{a}}$ & - & n.a. & ATCC 25923 \\
\hline S. aureus ${ }^{\mathrm{a}}$ & n.a. & - & ATCC 6538 \\
\hline S. aureus (MRSA) & - & n.a. & NEQAS 4937/98 \\
\hline S. aureus $(\mathrm{MRSA})^{\mathrm{b}}$ & n.a. & - & ATCC 43300 \\
\hline Staphylycoccus epidermidis ${ }^{\mathrm{a}}$ & - & n.a. & ATCC 49461 \\
\hline Enterococcus faecalis ${ }^{\mathrm{a}}$ & - & n.a. & ATCC 29212 \\
\hline E. faecalis (VRE) ${ }^{a}$ & - & n.a. & EARSS UA605/01 \\
\hline E. faecalis ${ }^{\mathrm{a}}$ & - & n.a. & EARSS UA 1527/01 \\
\hline Streptococcus pyogenes $(\mathrm{A})^{\mathrm{a}}$ & - & n.a. & ATCC 19615 \\
\hline Streptococcus agalactiae $(\mathrm{B})^{\mathrm{a}}$ & - & n.a. & NEQAS 6098/01 \\
\hline \multicolumn{4}{|l|}{ Gram-positive rods } \\
\hline Arcanobacterium haemolyticum ${ }^{\mathrm{a}}$ & - & n.a. & Lab quality strain $237 / 95$ \\
\hline \multicolumn{4}{|l|}{ Gram-negative rods } \\
\hline Escherichia coli ${ }^{\mathrm{a}}$ & +++ & n.a. & ATCC 25922 \\
\hline E. coli ${ }^{\mathrm{b}}$ & n.a. & - & ATCC 10538 \\
\hline Enterobacter cloacae ${ }^{a}$ & ++ & n.a. & ATCC 23355 \\
\hline Klebsiella pneumoniae ${ }^{a}$ & +++ & n.a. & ATCC 13883 \\
\hline Proteus vulgaris ${ }^{\mathrm{a}}$ & - & n.a. & ATCC 8427 \\
\hline Proteus mirabilis $^{\mathrm{a}}$ & +++ & n.a. & ATCC 12453 \\
\hline Pseudomonas aeruginosa $^{\mathrm{a}}$ & +++ & n.a. & ATCC 27853 \\
\hline P. aeruginosa ${ }^{\mathrm{b}}$ & n.a. & - & ATCC 15442 \\
\hline Bacillus subtilis ${ }^{\mathrm{b}}$ & n.a. & - & ATCC 6633 \\
\hline \multicolumn{4}{|l|}{ Dermatophytes ${ }^{\mathrm{c}}$} \\
\hline Trichophyton rubrum & - & n.a. & ATCC 28188 \\
\hline T. rubrum & - & n.a. & Clinical isolate $05 \mathrm{PI} 5613$ \\
\hline Trichophyton mentagrophytes & - & n.a. & ATCC 9533 \\
\hline Trichophyton tonsurans & - & n.a. & Lab quality strain $426 / 2000$ \\
\hline Microsporum canis & - & n.a. & Clinical isolate 05PI5908 \\
\hline Epidermophyton floccosum & - & n.a. & Clinical isolate 05PI5877 \\
\hline \multicolumn{4}{|l|}{ Yeasts $^{\mathrm{c}}$} \\
\hline Candida albicans & +++ & n.a. & ATCC 90028 \\
\hline C. albicans ${ }^{b}$ & n.a. & - & ATCC 10231 \\
\hline Candida glabrata & ++ & n.a. & NL 2238 \\
\hline Candida krusei & ++ & n.a. & ATCC 6258 \\
\hline Candida parapsilosis & +++ & n.a. & ATCC 22019 \\
\hline Candida dubliniensis & +++ & n.a. & NEQAS 5525/2000 \\
\hline Candida tropicalis & +++ & n.a. & Lab quality strain $425 / 2000$ \\
\hline \multicolumn{4}{|l|}{ Opportunistic fungal species ${ }^{\mathrm{c}}$} \\
\hline Fusarium solani & +++ & n.a. & NEQAS 5204/1999 \\
\hline Chrysosporium keratinophilum & +++ & n.a. & Clinical isolate 05PI5899 \\
\hline
\end{tabular}

${ }^{a}$ Growth in fastidious anaerobe broth (FAB) liquid medium in the presence of $10 \%(w / w)$ resin-salve medium in Mueller-Hinton agar after $16-20 \mathrm{~h}$ incubation.

${ }^{\mathrm{b}}$ At a 4-day time point in the presence of $10 \%(\mathrm{w} / \mathrm{w})$ resin-salve medium.

${ }^{\circ}$ Growth in the Roswell Park Memorial Institute (RPMI) agar medium with the presence of $50 \%(\mathrm{w} / \mathrm{w})$ resin-salve medium.

A, the group A streptococcus bacterium; B, the group B streptococcus bacterium; ATCC, American Type Culture Collection; EARSS, European Antimicrobial Resistance Surveillance System; EP, European Pharmacopoeia; MRSA, methicillin-resistant $S$. aureus; NEQAS, National External Quality Assessment Service; VRE, vancomycin-resistant enterococci; - , no visible growth or distinct inhibition zone; +, slight growth; ++, moderate growth or potential inhibition zone; +++ , heavy growth or indistinguishable inhibition zone; n.a., not analyzed. 
the 6-month follow up, and the successful eradication within 1 month of pathogenic bacteria cultured from the ulcers at study entry. The inclusion criterion was one or several severe pressure ulcers (grade II-IV) with or without infection. The exclusion criteria were a life expectancy of less than 6 months or an end-stage malignant disease. Safety was assessed in terms of adverse event reports. Thirteen patients in the resin group and nine patients in the control group completed the 6-month trial. There were eight ( 8 of $21 ; 38 \%$ ) dropout patients in the resin group (one patient had two ulcers) and seven dropout patients $(7$ of $16 ; 44 \%)$ in the control group. The reasons for dropping out from the resin group were three deaths (38\% of all dropouts in the resin group), two admissions to operative treatment $(25 \%)$, one allergic skin reaction (13\%), one misdiagnosis (13\%), and one patient-based refusal without any specific cause (13\%). The reasons for dropping out from the control group were four deaths (57\%), two patient-based refusals without any specific cause (29\%), and one patient-based refusal because of randomization to the control group (14\%). A subgroup analysis among the dropouts between the resin and control treatment groups regarding patient- and ulcer-related characteristics at baseline did not show statistical differences.

At baseline, the dimension of the ulcers in terms of width and depth were $3.2 \mathrm{~cm}$ versus $4.2 \mathrm{~cm}$ $(p=0.387)$ and $5.2 \mathrm{~mm}$ versus $6.5 \mathrm{~mm}(p=0.580)$ in the resin group and control group, respectively. Surgical debridement at bedside under local anesthesia was performed five (28\%) times in resin group and seven (64\%) times in control group, respectively $(p=0.078)$. The difference between the pressure ulcer grades among the resin and control groups was not statistically significant either $(p=0.938)$. All ulcers healed in 12 out of 13 patients $(92 \%)$ in the resin group and in four out of nine patients (44\%) in the control group during the 6-month treatment period. Complete healing of the ulcers over time was more common in the resin group than in the control group (94\% vs. 36\%), and bacterial cultures from the ulcer area more often became negative within 1 month in the resin group. The observed differences in wound healing between the treatment groups were statistically significant. ${ }^{10}$

In 2012 , we reported the results of a prospective nonrandomized clinical trial that was designed to study healing rates, contributors to delayed wound healing, cost effectiveness, and incidence of allergic reactions when $10 \%(\mathrm{w} / \mathrm{w})$ resin salve (Abilar $^{\circledR}$ 10\% Resin Salve; Repolar Ltd., Espoo, Finland) was used topically to treat complicated chronic surgical wounds. The trial involved 23 patients whose wound healing after elective surgery was delayed. The patients were assigned to resin salve treatment within the control visit at the surgical outpatient department. The primary outcome measures were the rate of wound healing and the number of days to complete wound healing. The study result was a healing rate of $100 \%$ of chronic surgical wounds within a mean healing time of 43 days. $^{11}$

\section{Current evidence for antimicrobial spectrum of resin}

In vitro. Table 1 gives a summary of the antibacterial properties of the resin. Antibacterial activity covers common nosocomial infections, such as surgical wound infections caused by methicillinresistant $S$. aureus (MRSA) and vancomycinresistant Enterococcus (VRE) species. ${ }^{12-15}$

In vivo. Resin's capacity to eradicate bacteria from chronic wounds has been demonstrated in vivo in the randomized, controlled clinical setting in patients whose severe pressure ulcers were treated with the resin salve. ${ }^{10}$ Altogether, 28 pressure ulcers

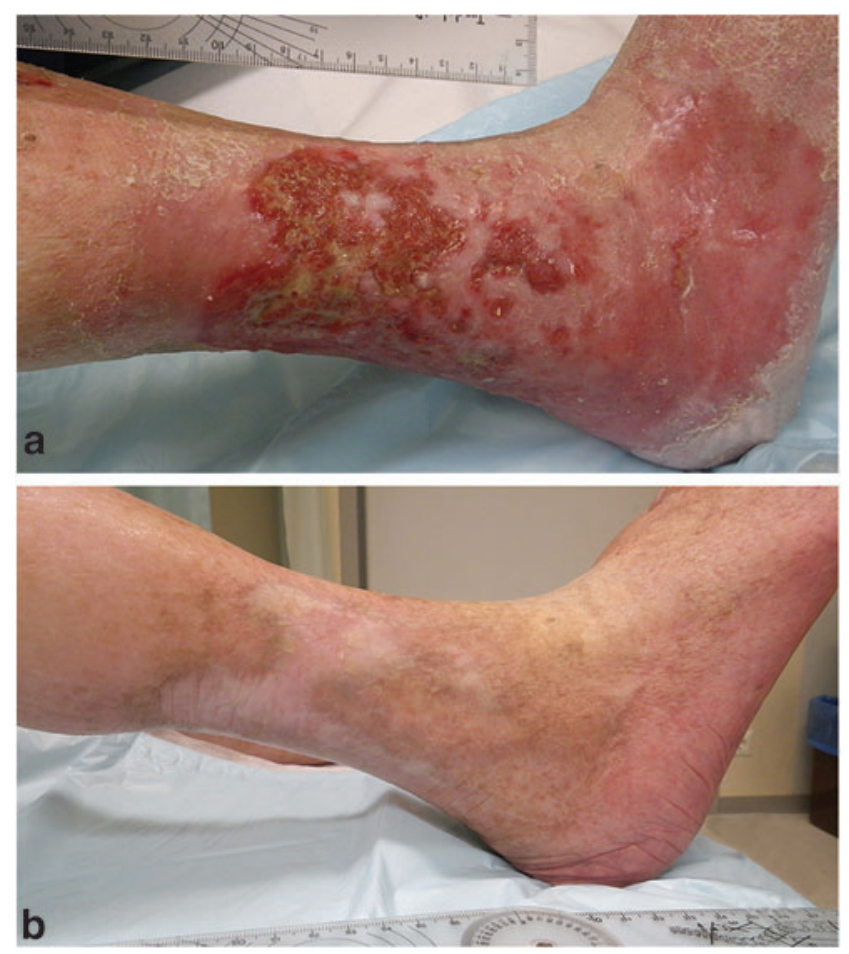

Figure 7. An 80-year old female who suffered from severe rheumatoid arthritis and refractory venous leg ulcer that had been surgically operated twice and treated with local wound care preparations for several years (a). Leg ulcer 7 months after initiation of the treatment with resin salve (b). To see this illustration in color, the reader is referred to the web version of this article at www.liebertpub.com/wound 
were contaminated with 10 different bacterial strains at the beginning of the study. The number of contaminated ulcers was 10 after 1-month treatment period (64\% reduction) and only two at the endpoint after 6 months of treatment (93\% reduction). However, interpretation of the result may be biased and open to criticism because of concomitantly administered oral antibiotic treatment in four patients.

\section{CONCLUSIONS}

Approximately $70 \%$ of the scientifically tested pharmaceuticals and local treatment products that we use nowadays for various medical conditions still originate in the natural world. ${ }^{29} \mathrm{We}$ are inclined to forget, for example, that the bases of modern antibiotic treatment (e.g., vancomycin, amphotericin B) and immunosuppressive drug therapy (e.g., cyclosporine, tacrolimus), as well as local wound care options (trimethylglycine or glycine betaine), have been uncovered by individual researchers or groups making empiric observations that, step by step, have led to the scientific breakthrough. ${ }^{30-33}$ Nowadays, efforts to find new therapeutics such as new antibiotics seem to have shifted back to the natural world. This shift has resulted in a number of newly discovered treatment options for several refractory medical conditions with unique scaffolds or novel mechanisms of action. ${ }^{34,35}$

It is indisputable that the establishment of the efficacy of spruce resin in the treatment of chronic wounds fulfils the criterion of a new innovation of an old folkloristic medical therapy. Although resin-related basic, clinical, and applied research results give strong evidence for the mechanisms of action, clinical effectiveness, and feasibility of resin treatment for its current indications (Fig. 7), several unsolved questions remain: The next targets of our research group are to individualize pharmacologically active compounds that are responsible for antimicrobial activity of resin, and to study the exact molecular mechanisms of action by which resin promotes cellular regeneration and epithelialization during the wound-healing process. We also aim to investigate potential antimicrobial properties of resin and its derivatives against the most ominous multidrug-resistant betalactamase-including carbapenemases and metallo$\beta$-lactamases-producing bacteria. From a clinical perspective, repeated randomized and controlled clinical trials are needed.

\section{AUTHOR DISCLOSURE AND GHOSTWRITING}

Both authors have completed the ICMJE Uniform Disclosure Form and declare: J.J.J. and A.S. are shareholders of Repolar Ltd., a Finnish company established to develop and market resinbased products for medical purposes. The content of this article was expressly written by J.J.J. and A.S. No ghostwriters were used to write this article.

\section{ABOUT THE AUTHORS}

Janne J. Jokinen, MD, PhD is a cardiac surgeon at the Helsinki University Hospital, Helsinki, Finland. Arno Sipponen is an orthopedic surgeon at the Päijät-Häme Central Hospital, Lahti, Finland. Both authors worked in the early 2000 s as general practitioners in the municipality of Kolari in Finnish Lapland. During this time, they became familiar with an old folkloristic therapy, in which salve prepared from Norway spruce ( $P$. abies) resin was used in the treatment of chronic, refractory wounds, sores, pressure ulcers, acute infected traumatic and surgical wounds, punctured abscesses, and minor burns. Although the old medical records revealed that several generations of physicians empirically perceived the efficacy of resin salve treatment in wound healing-as the authors did at that time-it was a surprise to discover that neither basic science nor clinical studies about resin salve treatment in wound care existed in the medical literature at that time. In 2002, the authors-at the instigation of Dr. Sipponendecided to launch investigations on the properties of Norway spruce resin, its use as therapy, and its 
therapeutic applications in comparison with modern medicine. In 2013, the interdisciplinary research group that was involved in the resin salve project consisted of physicians, microbiologists, pharmacologists, forestry specialists, chemists, and technical professionals.

\section{REFERENCES}

1. Surgical Dressing Manufacturer's Association (SDMA): The Surgical Materials Testing Laboratory (SMTL) dressings datacards. Available at: www .dressings.org (last accessed August 23, 2013).

2. Lohi J, Sipponen A, and Jokinen JJ: Local dressings for pressure ulcers: what is the best tool to apply in primary and second care? J Wound Care 2010; 19: 123.

3. Harding KG, Morris $\mathrm{HL}$, and Patel GK: Science, medicine and the future: healing chronic wounds. BMJ 2002; 324: 160.

4. Fonder MA, Lazarus GS, and Cowan DA: Treating the chronic wound: a practical approach to the care of nonhealing wounds and wound care dressings. J Am Acad Dermatol 2008; 58: 185.

5. American Society of Plastic Surgeons: Evidencebased clinical practice guideline: chronic wounds of the lower extremity. National Guideline Clearinghouse, 2007. Available at: www.guideline .gov (last accessed August 23, 2013).

6. Markova A and Mostow EN: US skin disease assessment: ulcer and wound care. Dermatol Clin 2012; 30: 107

7. Hjort A and Gottrup F: Cost of wound treatment to increase significantly in Denmark over the next decade. J Wound Care 2010; 19: 173.

8. Sipponen A and Lohi J: [Lappish resin salve treatment-"new" therapy for pressure sores? Ideal folk medicine]. Finn Med J 2003; 38: 3775. (In Finnish.)

9. Sipponen A, Jokinen JJ, and Lohi J: Resin salve from the Norwegian spruce tree: a "novel" method for the treatment of chronic wounds. J Wound Care 2007; 16: 72.

10. Sipponen A, Jokinen JJ, Sipponen P, Papp A, Sarna $S$, and Lohi J: Beneficial effect of resin salve in treatment of severe pressure ulcer-a prospective, randomized and controlled multicenter trial. Br J Dermatol 2008; 158: 1055.

11. Sipponen A, Kuokkanen O, Tiihonen R, Kauppinen $\mathrm{H}$, and Jokinen JJ: Natural coniferous resin salve used to treat complicated surgical wounds: pilot clinical trial on healing and costs. Int J Dermatol 2012; 51: 726

12. Sipponen P, Sippponen A, Lohi J, Soini M, Tapanainen $\mathrm{R}$, and Jokinen $\mathrm{JJ}$ : Natural coniferous resin lacquer in treatment of toenail onychomycosis: an observational study. Mycoses 2013; 56: 289

13. Rautio M, Sipponen A, Peltola R, Lohi J, Jokinen JJ, Papp A, Carlson P, and Sipponen P: Antibacterial effects of home-made rosin salve from Norway spruce (Picea abies). APMIS 2007; 115: 335.

14. Rautio M, Sipponen A, Lohi J, Lounatmaa K, Koukila-Kähkölä $\mathrm{P}$, and Laitinen $\mathrm{K}$ : In vitro fungi- static effects of natural coniferous resin from Norway spruce (Picea abies). Eur J Clin Microbiol Infect Dis 2012; 31: 1783.

15. Sipponen A and Laitinen $\mathrm{K}$ : Antimicrobial properties of natural coniferous rosin in the European Pharmacopoeia challenge test. APMIS 2011; 119: 720.

16. Sipponen A, Peltola R, Jokinen JJ, Laitinen K, Lohi J, Rautio M, Männistö M, Sipponen $P$, and Lounatmaa K: Effects of Norway spruce (Picea abies) resin on cell wall and cell membrane of Staphylococcus aureus. Ultrastruct Pathol 2009; 33: 128.

17. Sipponen A, Rautio M, Jokinen JJ, Laakso T, Saranpää $\mathrm{P}$, and Lohi J: Resin salve from Norway spruce-a potential method to treat infected chronic skin ulcers? Drug Metab Lett 2007; 1: 143.

18. Cockshott WP: The history of the treatment of burns. Surg Gynecol Obstet 1956; 102: 116.

19. Sharma BR, Singh VP, Bangar S, and Gupta N: Septicemia: the killer of burns patients. Am $\mathrm{J}$ Infect Dis 2005; 1: 132.

20. Perret L: [Benedictus Olai: A useful book of medicine, 1578. A quadricentennial. Some aspects of sixteenth-century healing arts]. Nord Medicinhist Arsb 1980; 6: 118. (In Swedish.)

21. Clinical and Laboratory Standards Institute CLSI/ NCCLS: Performance standards for antimicrobial disk susceptibility test for bacteria that grow aerobically; approved standard-6th Edition. CLSI/NCCLS document M2-A8. Wayne, PA: Clinical and Laboratory Standards Institute, 2005.

22. Murray PR, Baron EJ, Jørgensen JH, Pfaller MA, and Yolken RH (eds): Dilution testing: agar method. In: Manual of Clinical Microbiology, 8th edition. Washington, DC: ASM Press, 2003, p. 1111

23. European Pharmacopoeia (Eur. Ph.): Efficacy of Antimicrobial Preservation, general chapter 5.1.3. Council of Europe, Strasbourg Cedex, France, 2005.

24. Efficacy test and evaluation of the preservation of a cosmetic product shall conform to IS011930: 2012, Cosmetics - Microbiology - Evaluation of the antimicrobial protection of a cosmetic product. Available at: www.iso.org/obp/ui/\#iso:std:iso:11930:ed-1: v1:en (last accessed December 19, 2013).

25. Lounatmaa K: Electron microscopic methods for the study of bacterial surface structures. In: Enterobacterial surface antigens: methods for molecular characterization, edited by Korhonen T, Dawes EA, and Mäkelä PH. Amsterdam: Elsevier, 1985, pp. 243-261.

26. Estlander T, Jolanki R, Alanko K, and Kanerva L: Occupational allergic contact dermatitis caused by wood dusts. Contact Dermat 2001; 44: 213.
27. Majamaa $\mathrm{H}$ and Viljanen P: Occupational facial allergic contact dermatitis caused by Finnish pine and spruce wood dusts. Contact Dermat 2004; 51 : 157.

28. European Pressure Ulcer Advisory Panel: Pressure ulcer prevention. Available at: www.epuap.org/ guidelines/Final_Quick_Prevention.pdf (last accessed August 23, 2013).

29. Newman DJ and Cragg GM: Natural products as sources of new drugs over the last 25 years. $J$ Nat Prod 2007; 70: 461.

30. Mahady GB: Medical plants for the prevention and the treatment of a bacterial infections. Curr Pharm Des 2005; 11: 2405.

31. Rios JL and Recio MC: Medicinal plants and antimicrobial activity. J Ethnopharmacol 2005; 6: 80.

32. Kino $T$, Hatanaka $H$, Hashimoto $M$, Nishiyama $M$, Goto T, Okuhara M, Kohsaka M, Aoki H, and Imanaka H: FK-506, a novel immunosuppressant isolated from a Streptomyces. Fermentation, isolation, and physico-chemical and biological characteristics. J Antibiot (Tokyo) 1987; 40: 1249.

33. Sakamoto A and Murata N: The role of glycine betaine in the protection of plants from stress: clues from transgenic plants. Plant Cell Environ 2002; 25: 163.

34. Clardy J, Fischbach MA, and Walsh CT: New antibiotics from bacterial natural products. Nat Biotechnol 2006; 24: 1541

35. Butler MS: Natural products to drugs: natural product-derived compounds in clinical trials. Nat Prod Rep 2008; 25: 475.

\section{Abbreviations and Acronyms}

ATCC $=$ American Type Culture Collection

$\mathrm{CLSI}=$ Clinical and Laboratory Standards Institute

$\mathrm{cfu}=$ colony-forming units

EARSS $=$ European Antimicrobial Resistance Surveillance System

$E P=$ European Pharmacopoeia

$E P U A P=$ European Pressure Ulcer Advisory Panel

$F A B=$ fastidious anaerobe broth

$M I C=$ minimal inhibitory concentration

$\mathrm{MFI}=$ mean fluorescence intensity

MRSA $=$ methicillin-resistant $S$. aureus

NEQAS $=$ National External Quality Assessment Service

$\mathrm{RPMI}=$ Roswell Park Memorial Institute

SEM = scanning electron microscopy

$\mathrm{TEM}=$ transmission electron microscopy

VRE $=$ vancomycin-resistant enterococci 